\title{
PERENCANAAN TEMPAT PERHENTIAN ANGKUTAN UMUM DI JALAN WILAYAH PERKOTAAN PURWOKERTO
}

Budiharso Hidayat, ATD, MT

Dosen STTD

J1. Raya Setu Km. 3,5 Cibuntu, Cibitung, Bekasi 17520

Telp./fax. 021 8254640Barat Telp : 021-8254640

E-mail : aim.harso@gmail.com info.p3m.sttd@gmail.com

\author{
Ekki Ryan Wahyudi, S.SiT \\ Prodi Transdar STTD \\ J1. Raya Setu Km. 3,5 Cibuntu, \\ Cibitung, Bekasi 17520 \\ Telp./fax. 021 8254640Barat \\ Telp : 021-8254640
}

\author{
Ir. Djoko Septanto, MM \\ Dosen STTD \\ J1. Raya Setu Km. 3,5 Cibuntu, \\ Cibitung, Bekasi 17520 \\ Telp./fax. 021 8254640Barat \\ Telp : 021-8254640
}

\begin{abstract}
Urban Area of Purwokerto is the center of activity in Banyumas Region, it make that area need a good transport system for a good service of the people mobility, with the good public transport system, need to be supported with good infrastructure as well, in this case that a public transport stop. Currently the performance stop in Cities Purwokerto does not correspond to the needs of society as well as technical guideline. With the number 29 route and 273 fleets, but there are only 8 stops, hence the need to plan for the construction of bus stop. Construction of public transport stops adjusted to the needs of society in accordance with the characteristics Purwokerto passenger and public transport driver. Use development priorities with emphasis on the amount of demand, land use and walking distance. Budget Plan calculated for all stop the plan .
\end{abstract}

Keywords : Public transport stop, Passenger and driver characteristics, Priority, Budget Plan

\begin{abstract}
ABSTRAK
Wilayah Perkotaan Purwokerto merupakan pusat kegiatan dari kabupaten Banyumas sehingga wilayah tersebut memerlakan sistem transportasi yang baik agar mobilitas masyarakat terlayani dengan baik, dengan adanya sistem angkutan umumnya yang baik, perlu di dukung dengan prasarana yang baik juga, dalam hal ini yakni tempat perhentian angkutan umum. Saat ini kinerja halte di Wilayah Perkotaan Purwokerto tidak sesuai dengan kebutuhan masyarakat maupun pedoman teknis. Dengan jumlah 29 trayek dan 273 armada, tetapi hanya ada 8 halte, maka dari itu perlunya perencanaan untuk pembangunan halte. Pembangunan tempat perhentian angkutan umum di sesuaikan dengan kebutuhan masyarakat Purwokerto yang sesuai dengan karakteristik penumpang maupun pengemudi angkutan umum. Pembangunan menggunakan skala prioritas dengan menitikberatkan jumlah demand, tata guna lahan dan jarak berjalan kaki. Rencana Anggaran Biaya di hitung untuk semua halte rencana.
\end{abstract}

Kata Kunci : Tempat Perhentian Angkutan Umum, Karakteristik Penumpang dan Pengemudi, Prioritas, Rencana Anggaran Biaya

\section{PENDAHULUAN}

Penyediaan fasilitas pendukung dalam penyelenggaraan lalu lintas dan angkutan jalan merupakan salah satu hal yang penting untuk membantu mewujudkan pengembangan pada bidang transportasi. Tempat perhentian angkutan umum merupakan bagian dari fasilitas pendukung yang berfungsi sebagai tempat pemberhentian kendaraan bermotor umum untuk menaikkan dan menurunkan penumpang, dimana keberadaannya sangat diperlukan di sepanjang rute yang dilalui oleh angkutan umum. Berdasarkan hasil 
survei inventarisasi angkutan umum di Wilayah Perkotaan Purwokerto mempunyai tempat perhentian angkutan umum yaitu halte sebanyak 8 unit yang belum seluruhnya sesuai dengan pedoman teknis perekayasaan tempat perhentian kendaraan penumpang umum serta peletakan halte belum menyebar keseluruh jaringan jalan yang dilayani oleh angkutan umum di Wilayah Perkotaan Purwokerto. Hal ini menyebabkan para pengemudi angkutan umum menurunkan dan menaikkan penumpang di tempat yang tidak semestinya, sehingga mengakibatkan berkurangnya fungsi tempat perhentian angkutan umum yang aman, nyaman, dan tertib.

Mengingat pentingnya peranan angkutan umum dapat dikatakan bahwa perkembangan suatu kota sangat dipengaruhi oleh penyediaan fasilitas angkutan umum. Maka keberadaan tempat perhentian angkutan umum harus diperhatikan karena merupakan salah satu prasarana angkutan umum yang penting sehingga para penumpang akan merasa nyaman pada saat menunggu angkutan umum.

\section{TINJAUAN PUSTAKA}

\section{Pengertian Transportasi}

Transportasi dapat diartikan sebagai kegiatan yang memungkinkan perpindahan manusia dan atau barang dari suatu tempat ke tempat lainnya. Dari pengertian tersebut, maka setiap transportasi mengakibatkan terjadinya perpindahan dan pergerakan, yang berarti terjadi lalu lintas (Soejono, 1990).

Sementara menurut Fidel Miro (2005) Transportasi merupakan usaha memindahkan, menggerakkan, mengangkut atau mengalihkan suatu objek dari suatu tempat ke tempat lain dimana di tempat lain ini objek tersebut label bermanfaat atau dapat berguna untuk tujuan-tujuan tertentu.

Jadi secara garis besar,Transportasi merupakan suatu usaha atau kegiatan untuk memindahkan orang dan/ barang dari suatu tempat ke tempat lain sehingga menimbulkan pergerakan yang disebut lalu lintas.

\section{Pengertian Tempat Perhentian Angkutan Umum}

Tempat perhentian angkutan umum (TPAU) terdiri dari halte dan tempat perhentian bus. Halte adalah tempat perhentian kendaraan penumpang umum untuk menurunkan dan/atau menaikkan penumpang yang dilengkapi dengan bangunan. Tempat perhentian bus (bus stop) adalah tempat untuk menurunkan dan/atau menaikkan penumpang (SK Dirjen Hubdat No.271/HK.105/DRJD/96).

\section{Pengertian Halte}


Menurut Lembaga Pengabdian Kepada Masyarakat (LPKM) ITB tahun 1997, halte adalah lokasi di mana penumpang dapat naik ke dan turun dari angkutan umum dan lokasi di mana angkutan umum dapat berhenti untuk menaikan dan menurunkan penumpang, sesuai dengan pengaturan operasional.

Menurut Dirjen Bina Marga 1990 tahun, halte adalah bagian dari perkerasan jalan tertentu yang digunakan untuk pemberhentian sementara bus, angkutan penumpang umum lainnya pada waktu menaikan dan menurunkan penumpang.

Jadi secara garis besar halte merupakan bagian dari perkerasan jalan tertentu dimana angkutan umum dapat berhenti untuk menurunkan dan/atau menaikkan penumpang yang dilengkapi dengan bangunan sesuai dengan pengaturan operasional.

\section{Karakteristik Penumpang dan Pengemudi Angkutan Umum}

Penumpang dan Pengemudi yang dimaksud adalah semua penumpang dan pengemudi angkutan umum yang ada di Wilayah Perkotaan Purwokerto. Pada umumnya perjalanan penumpang bersifat home base dan merupakan perjalanan simple chain. Perjalanan yang dimulai dan diakhiri dalam waktu bersamaan dengan rumah sebagai asal dan tujuan perjalanan. Sedangkan pengemudi biasanya senang pada jam - jam operasi tertentu yakni waktu anak sekolah berangkat dan pulang sekolah.

\section{Pengertian Rencana Anggaran Biaya}

Menurut Sugeng Djojowirono, 1984, Rencana Anggaran Biaya (RAB) merupakan perkiraan biaya yang diperlukan untuk setiap pekerjaan dalam suatu proyek konstruksi sehingga akan diperoleh biaya total yang diperlukan untuk menyelesaikan suatu proyek.

J. A. Mukomoko, dalam bukunya Dasar Penyusunan Anggaran Biaya Bangunan, 1987 Rencana Anggaran Biaya (RAB) adalah perkiraan nilai uang dari suatu kegiatan (proyek) yang telah memperhitungkan gambar-gambar bestek serta rencana kerja, daftar upah, daftar harga bahan, buku analisis, daftar susunan rencana biaya, serta daftar jumlah tiap jenis pekerjaan.

\section{PEMBAHASAN}

\section{Data}

Terdapat 2 (dua) jenis data yang digunakan dalam melakukan analisis perencanaan tempat perhentian angkutan umum di jalan wilayah perkotaan purwokerto, yaitu:

1. Data Sekunder 
Data sekunder adalah data yang diperoleh dari instansi-instansi terkait yang di dapat secara langsung maupun tidak langsung. Data-data yang diperlukan antara lain data tata guna lahan (Bappeda), data jaringan trayek angkutan umum eksisting (Dinas Perhubungan), data jaringan jalan (Dinas Pekerjaan Umum).

\section{Data Primer}

Data primer adalah data yang diperoleh dari hasil survei lapangan yang dilakukan oleh surveyor. Data yang diperoleh antara lain data dimensi tempat perhentian angkutan umum eksisting (Survei Inventarisasi), Karakteristik penumpang dan pengemudi angkutan umum wilayah perkotaan Purwokerto (Survei Wawancara), dan loading profile angkutan umum (Survei Dinamis Angkutan Umum)

\section{Analisis data}

1. Perhitungan Sampel Wawancara

Diketahui populasi jumlah penumpang angkutan kota dan bus AKDP yang menjadi objek penelitian adalah sebesar 3530 orang, yang di dapat dari jumlah penumpang orang/hari. Maka dapat di tentukan sampel sebesar :

$$
\mathrm{n}=3530 /(1+(3530 \times(\llbracket 0.05 \rrbracket \wedge 2)))
$$

= 359, 29 kemudian dibulatkan menjadi 360 sampel penumpang.

Diketahui populasi jumlah pengemudi yang menjadi objek penelitian adalah sebesar 273 orang ( Sumber ; Koperakop Purwokerto, 2014). Maka dapat di tentukan sampel sebesar :

$\mathrm{n}=273 /(1+(273 \times(\llbracket 0.05 \rrbracket \wedge 2)))$

$=162,25$ kemudian dibulatkan menjadi 163 sampel pengemudi

2. Karakteristik Penumpang Angkutan Umum

Karakteristik penumpang angkutan umum di wilayah Perkotaan Purwokerto yakni penumpang terbanyak adalah perempuan dengan umur rata- rata antara umur 15 sampai 25 tahun yang lebih memilih halte dibandingkan bus stop dikarenakan penumpang yang menginginkan nyaman dalam menunggu angkutan umum yang dirasa cukup lama. Karakteristik penumpang sendiri mayoritas adalah untuk pergi bersekolah dengan jarak kemauan berjalan kaki 100 sampai 150 meter dari asal maupun tujuan. Dari hasil tadi dapat dipastikan penumpang bersedia menggunakan fasilitas tempat perhentian angkutan umum dengan prioritas pembangunan yaitu berada di kawasan sekolah yang dilengkapi dengan fasilitas fasilitas tambahan, seperti tempat duduk yang paling utama dan fasilitas lain penunjang fasilitas utama 
3. Karakteristik Pengemudi Angkutan Umum

Karakteristik pengemudi angkutan umum di wilayah perkotaan Purwokerto yakni latar belakang pengemudi paling banyak adalah SMA/SMK/MAN Sederajat dikarenakan dengan latar belakang SMA dan kemampuan yang terbatas dirasa sulit untuk mencari pekerjaan, maka dari itu mereka lebih memilih menjadi pengemudi angkutan umum karena hanya keahlian mngemudi yang mereka punya. Pengemudi bersedia menaikkan dan menurunkan penumpang hanya di tempat perhentian yang di sediakan dengan alasan agar penumpang berkumpul di satu tempat dan kepastian bahwa penumpang hanya menunggu angkutan di tempat perhentian yang sudah. Rata - rata pengemudi mau untuk menunggu penumpang adalah 5-10 menit dan lama proses naik turun penumpang yakni kurang dari 1 menit, dikarenakan penumpang terbanyak adalah anak sekolah maka prioritas tempat perhentian sebaiknya di letakkan di dekat kawasan sekolah, agar para pelajar dapat terkumpul di satu tempat nantinya.

4. Evaluasi Tempat Perhentian Angkutan Umum

Berdasarkan hasil survei inventarisasi prasarana angkutan umum di Wilayah Perkotaan Purwokerto didapatkan hasil bahwa Wilayah Perkotaan Purwokerto mempunyai 8 Halte yang terletak pada 7 ruas jalan. Untuk Dimensi halte di Wilayah Perkotaan Purwokerto berbeda, berikut dimensi halte di Wilayah Perkotaan Purwokerto:

Tabel 1: Dimensi Halte eksisting wilayah Perkotaan Purwokerto

\begin{tabular}{lcccc}
\hline \multicolumn{1}{c}{ Titik Halte } & $\begin{array}{c}\text { panjang } \\
(\mathrm{m})\end{array}$ & $\begin{array}{c}\text { lebar } \\
(\mathrm{m})\end{array}$ & $\begin{array}{c}\text { tinggi } \\
(\mathrm{m})\end{array}$ & $\begin{array}{c}\text { Kode } \\
\text { dimensi } \\
\text { halte }\end{array}$ \\
\hline MAN 2 Purwokerto & 3 & 1,5 & 2,5 & $\mathrm{~A}$ \\
$\begin{array}{l}\text { SMAN 1 } \\
\text { Purwokerto }\end{array}$ & 4,5 & 1,5 & 2,5 & $\mathrm{~B}$ \\
$\begin{array}{l}\text { STAIN Sunan } \\
\text { Ampel }\end{array}$ & 4,5 & 1,5 & 2,5 & $\mathrm{~B}$ \\
Unsoed & 3 & 1,5 & 2,5 & $\mathrm{~A}$ \\
Moro & 3 & 1,5 & 2,5 & $\mathrm{~A}$ \\
Kebon Dalem & 5,5 & 1,5 & 2,5 & $\mathrm{C}$ \\
SMKN 1 & 3 & 1,5 & 2,5 & $\mathrm{~A}$ \\
Purwokerto & & & & $\mathrm{B}$ \\
SMKN 2 & 4,5 & 1,5 & 2,5 & $\mathrm{~B}$ \\
Purwokerto & & & & \\
\hline
\end{tabular}


Tabel 2 : Jarak halte dari persimpangan terdekat sesuai SK.Dirjen Perhubungan Darat Nomor 271/ Hk.105/ DRJD 96

\begin{tabular}{|c|c|c|c|c|}
\hline Titik Halte & Ruas Jalan & Tata Guna Lahan & Lokasi Halte & Penilaian \\
\hline $\begin{array}{c}\text { MAN 2 } \\
\text { Purwokerto }\end{array}$ & $\begin{array}{c}\text { Jl. Jend } \\
\text { Sudirman XIII }\end{array}$ & Sekolah, Pemukiman & $\begin{array}{c}850 \mathrm{~m} \text { dari Simpang } \\
\text { Kasmandaka }\end{array}$ & Sesuai \\
\hline SMAN 1 & Jl. Gatot Subroto & Sekolah Pertokoan & 40 m dari Simpang & Tidak \\
\hline Purwokerto & III & seкогап, Pertokoan & Ksatrian & Sesuai \\
\hline $\begin{array}{l}\text { STAIN Sunan } \\
\text { Ampel }\end{array}$ & $\begin{array}{l}\text { Jl. Ahmad Yani } \\
\text { II }\end{array}$ & $\begin{array}{c}\text { Sekolah, Perkantoran, } \\
\text { Pemukiman }\end{array}$ & $\begin{array}{c}700 \text { m dari Simpang } \\
\text { Karang Kobar }\end{array}$ & Sesuai \\
\hline Unsoed & $\begin{array}{c}\text { Jl. HR } \\
\text { Bunyamin II }\end{array}$ & $\begin{array}{l}\text { Sekolah, Pertokoan, } \\
\text { Pemukiman }\end{array}$ & $\begin{array}{c}450 \text { m dari Simpang } \\
\text { Kampus }\end{array}$ & Sesuai \\
\hline Moro & $\begin{array}{c}\text { Jl. Perintis } \\
\text { Kemerdekaan I }\end{array}$ & Pertokoan & $\begin{array}{c}30 \text { m dari Simpang } \\
\text { Matahari }\end{array}$ & $\begin{array}{l}\text { Tidak } \\
\text { Sesuai }\end{array}$ \\
\hline Kebon Dalem & $\begin{array}{l}\text { Jl. Jend } \\
\text { Suprapto }\end{array}$ & Pasar, Pertokoan & $\begin{array}{c}300 \text { m dari Simpang } \\
\text { Selektif }\end{array}$ & Sesuai \\
\hline $\begin{array}{l}\text { SMKN } 1 \\
\text { Purwokerto }\end{array}$ & J1. Dr. Suparno & $\begin{array}{c}\text { Sekolah, Perkantoran, } \\
\text { Pemukiman }\end{array}$ & $\begin{array}{c}450 \mathrm{~m} \text { dari Simpang } \\
\text { GOR }\end{array}$ & Sesuai \\
\hline $\begin{array}{l}\text { SMKN } 2 \\
\text { Purwokerto }\end{array}$ & $\begin{array}{c}\text { Jl. Gatot Subroto } \\
\text { IV }\end{array}$ & Sekolah, Perkantoran & $\begin{array}{c}30 \text { m dari Simpang } \\
\text { Kebon Dalem }\end{array}$ & $\begin{array}{l}\text { Tidak } \\
\text { Sesuai }\end{array}$ \\
\hline
\end{tabular}

Tabel 3 : Jarak halte dari fasilitas penyeberangan pejalan kaki SK.Dirjen Perhubungan Darat Nomor 271/ Hk.105/ DRJD 96

\begin{tabular}{|c|c|c|c|c|}
\hline Titik Halte & Ruas Jalan & Tata Guna Lahan & Lokasi Halte & Penilaian \\
\hline $\begin{array}{c}\text { MAN 2 } \\
\text { Purwokerto }\end{array}$ & $\begin{array}{c}\text { Jl. Jend } \\
\text { Sudirman XIII }\end{array}$ & Sekolah, Pemukiman & $\begin{array}{c}5 \mathrm{~m} \text { dari Zebra } \\
\text { Cross }\end{array}$ & Sesuai \\
\hline $\begin{array}{l}\text { SMAN } 1 \\
\text { Purwokerto }\end{array}$ & $\begin{array}{l}\text { Jl. Gatot Subroto } \\
\text { III }\end{array}$ & Sekolah, Pertokoan & $\begin{array}{c}40 \mathrm{~m} \text { dari Zebra } \\
\text { Cross }\end{array}$ & Sesuai \\
\hline $\begin{array}{c}\text { STAIN } \\
\text { Sunan Ampel }\end{array}$ & $\begin{array}{l}\text { Jl. Ahmad Yani } \\
\text { II }\end{array}$ & $\begin{array}{c}\text { Sekolah, Perkantoran, } \\
\text { Pemukiman }\end{array}$ & $\begin{array}{l}10 \mathrm{~m} \text { dari Zebra } \\
\text { Cross }\end{array}$ & Sesuai \\
\hline Unsoed & $\begin{array}{c}\text { Jl. HR } \\
\text { Bunyamin II }\end{array}$ & $\begin{array}{l}\text { Sekolah, Pertokoan, } \\
\text { Pemukiman }\end{array}$ & $\begin{array}{c}450 \text { m dari Zebra } \\
\text { Cross }\end{array}$ & $\begin{array}{l}\text { Tidak } \\
\text { Sesuai }\end{array}$ \\
\hline Moro & $\begin{array}{l}\text { Jl. Perintis } \\
\text { Kemerdekaan I }\end{array}$ & Pertokoan & $\begin{array}{c}30 \mathrm{~m} \text { dari Zebra } \\
\text { Cross }\end{array}$ & Sesuai \\
\hline Kebon Dalem & $\begin{array}{c}\text { Jl. Jend } \\
\text { Suprapto }\end{array}$ & Pasar, Pertokoan & $\begin{array}{c}300 \mathrm{~m} \text { dari Zebra } \\
\text { Cross }\end{array}$ & $\begin{array}{l}\text { Tidak } \\
\text { Sesuai }\end{array}$ \\
\hline $\begin{array}{l}\text { SMKN } 1 \\
\text { Purwokerto }\end{array}$ & Jl. Dr. Suparno & $\begin{array}{c}\text { Sekolah, Perkantoran, } \\
\text { Pemukiman }\end{array}$ & $\begin{array}{c}20 \mathrm{~m} \text { dari Zebra } \\
\text { Cross }\end{array}$ & Sesuai \\
\hline $\begin{array}{c}\text { SMKN } 2 \\
\text { Purwokerto }\end{array}$ & $\begin{array}{l}\text { Jl. Gatot Subroto } \\
\text { IV }\end{array}$ & Sekolah, Perkantoran & $\begin{array}{c}30 \mathrm{~m} \text { dari Zebra } \\
\text { Cross }\end{array}$ & Sesuai \\
\hline
\end{tabular}


1. Analisa Kebutuhan Halte

Berdasarkan hasil analisis dapat diketahui bahwa 52 ruas jalan yang memenuhi jumlah penumpang minimal untuk dibangun suatu halte dikarenakan pada ruas jalan tersebut tata guna lahannya banyak yang merupakan pusat kegiatan seperti perkantoran, pertokoan dan sekolah sehingga dapat diambil kesimpulan bahwa ruas jalan tersebut merupakan titik kantong penumpang yang terdapat di wilayah Perkotaan Purwokerto.

2. Kapasitas Halte

Untuk menghitung kapasitas tempat perhentian angkutan umum (halte) digunakan standar ruang gerak per penumpang ditempat henti sesuai dengan SK. Dirjen Perhubungan Darat Nomor 271/ HK.105/ DRJD/ 96 tentang pedoman teknis perekayasaan tempat perhentian kendaraan penumpang umum yaitu $(0,9 \times 0,6) \mathrm{m} 2$ untuk karakteristik orang yang tidak membawa barang dan $(1,3 \times 0,9) \mathrm{m} 2$ untuk karakteristik orang yang membawa barang sesuai PM no. 3 Menteri Pekerjaan Umum tahun 2014. Penumpang menunggu di artikan sebagai penumpang yang naik dalam angkutan umum disetiap ruas jalan yang dilewati oleh trayek angkutan umum.

3. Kebutuhan Halte Berdasarkan jarak antar tempat henti

Berdasarkan data diatas dilakukan analisa mengenai jarak maksimum sesuai dengan intensitas tata guna lahan serta ukuran kota.

Perhitungan : (SK. Dirjen Perhubungan Darat Nomor : 271 /HK.105/DRJD /96.) dan kebutuhan masyarakat Wilayah Perkotaan Purwokerto.

4. Kebutuhan Fasilitas Tambahan Pada Halte

Dari hasil survei wawancara penumpang diketahui bahwa masyarakat Perkotaan Purwokerto membutuhkan fasilitas - fasilitas di dalam halte untuk menunjang kinerja dari halte tersebut, berikut adalah fasilitas yang dibutuhkan masyarakat Perkotaan Purwokerto :
a. Papan Informasi Trayek
b. Lampu Penerangan
c. Rambu Petunjuk
d. Pendingin Ruangan
e. Tempat duduk
f. Penjual (makanan, pulsa, dll)
g. Pagar
h. Fasilitas orang cacat 
5. Desain Halte
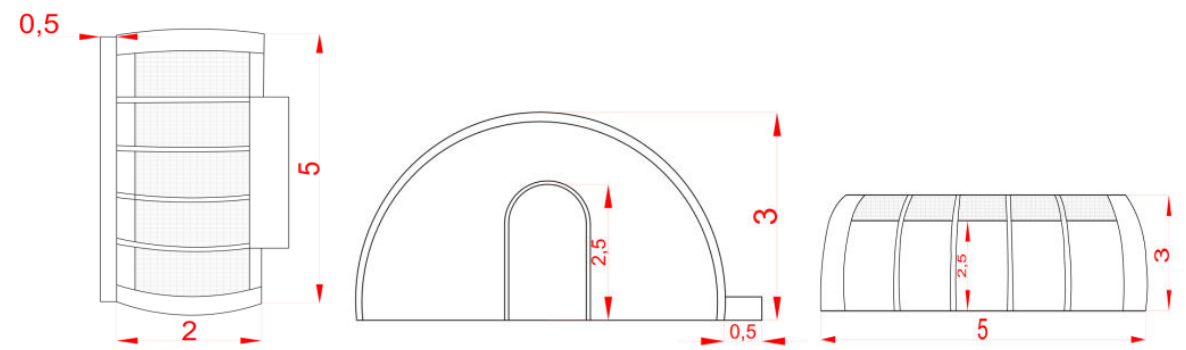

Gambar 1 : Gambar Tampak Atas, samping dan depan desain usulan halte

6. Prioritas Pembangunan

Untuk Prioritas pembangunan halte sendiri dikerjakan tidak dalam satu kurun waktu, tetapi dikerjakan bertahap dan dalam kurun waktu yang direncanakan yang telah disesuaikan dengan anggaran daerah dan anggaran dinas. Dari 83 halte yang di rencanakan, akan di bangun 23 halte pada tahun pertama, dan 20 halte untuk tahun berikutnya. 23 halte tersebut adalah halte yang memiliki jumlah permintaan yang besar, yakni jumlah naik turun penumpang yang tinggi dan lokasi halte yang berada di kawasan sekolah.

7. Rencana Anggaran Biaya

Rencana anggaran biaya dibuat agar kita dapat mengetahui seberapa banyak anggaran yang harus dikeluarkan untuk melakukan sebuah pembangunan, yang dalam hal ini yaitu halte. Rencana anggaran biaya kali ini menghitung prioritas halte yang dibangun untuk tahun pertama saja, dikarenakan untuk tahun berikutnya kita tidak dapat mengetahui seberapa banyak inflasi yang akan terjadi dan tidak bisa mengirakan kenaikan harga yang signifikan. Perhitungan Rencana Anggaran Biaya menggunakan Pedoman Analisa Harga Satuan Pekerjaan (AHSP) Kementerian Pekerjaan Umum, yakni analisa Burgelike Openbare Werken (BOW), Netherlands ; 1941. 


\section{REKAPITULASI}

I. Pekerjaan Persiapan

II. Pekerjaan Galian

III. Pekerjaan Pasangan \& Beton

IV. Pekerjaan Lantai

V. Pekerjaan Rangka Baja

VI. Pekerjaan Dinding

VII. Pekerjaan Atap

VIII. Pekerjaan lain - lain

IX. Finishing

Bouwsoms

Jasa Pemborong $10 \%$ x (A)

Rp 10.530.122.818(C)

Pajak Jasa $2 \frac{1}{2} \%$ x (C)

Aannemingsems

Dibulatkan
: Rp 47.211.425

: Rp 87.121.500

: Rp 2.489.907.165

: Rp 315.112.320

: Rp 778.189.000

: Rp 88.929.000

: Rp 815.350.053

: Rp 304.750 .000

: Rp 1.150.000

: Rp 9.572.838.926(A)

: Rp 957.283.893(B)

: Rp 263.253.070,46(D)

: Rp 10.793.375.888(E)

: Rp.793.375.900

Terbilang : Sepuluh miliar tujuh ratus sembilah puluh tiga juta tiga ratus tujuh puluh lima ribu sembilan ratus rupiah.

\section{KESIMPULAN}

1. Letak kantong penumpang berada pada 52 ruas dari 102 ruas jalan yang dilalui oleh angkutan umum di Wilayah Perkotaan Purwokerto.

2. Berdasarkan hasil analisa bahwa terdapat 3 halte yang tidak sesuai dengan standar teknis untuk jarak terhadap persimpangan, yaitu halte SMAN 1 Purwokerto, halte MORO, dan halte SMKN 2 Purwokerto dan terdapat 2 halte yang tidak sesuai dengan standar teknis untuk jarak terhadap fasilitas penyeberangan, yaitu halte Unsoed dan halte Kebon Dalem.

3. Wilayah Perkotaan Purwokerto membutuhkan 83 halte yang berdasarkan jumlah permintaan dan kebutuhan masyarakat Wilayah Perkotaan Purwokerto.

4. Dari hasil analisa diperoleh bahwa jenis halte yang dipilih adalah Enclosed halte, yakni bangunan halte yang memiliki sisi dinding lebih dari satu dan juga atapnya didukung oleh dari satu sisi dinding dan desain halte di rancang sesuai dengan permintaan dan kebutuhan masyarakat Wilayah Perkotaan Purwokerto. 
5. Berdasarkan hasil analisa pembangunan halte dikerjakan secara bertahap dengan membangun 23 halte di tahun pertama dan 20 halte di tahun berikutnya. Dengan memperhatikan demand terbesar tiap kantong penumpang dan tata guna lahan kawasan sekolah.

6. Rencana Anggaran Biaya dihitung hanya untuk pembangunan tahun pertama, dikarenakan untuk tahun berikutnya tidak mampu ditaksir seberapa besar inflasi harga dari tiap biaya yang akan dikeluarkan dengan Rencana Anggaran Biaya pembangunan halte untuk tahun pertama yaitu sebesar Rp 10.793.375.900.

\section{DAFTAR PUSTAKA}

1. 2009. Undang-Undang Republik Indonesia Nomor 22 Tahun 2009 Tentang

2. Lalu Lintas Dan Angkutan Jalan

3. _ 1996. Keputusan Direktur Jenderal Perhubungan Darat No.271/HK.105/DRJD/96 Tentang Pedoman Teknis Perekayasaan Tempat Perhentian Kendaraan Penumpang Umum, Direktorat Jenderal Perhubungan Darat, Jakarta.

4. ___ 2014. Peraturan Menteri Pekerjaan Umum Nomor 3 tahun 2014 tentang pedoman perencanaan, penyediaan, dan pemanfaatan prasarana dan sarana jaringan pejalan kaki di kawasan perkotaan, Kementerian Pekerjaan Umum, Jakarta

5. Kelompok PKL Kabupaten Banyumas,2015 , Laporan Umum Taruna Sekolah Tinggi Transportasi Darat Program D IV Transportasi Darat, Pola Umum Lalu Lintas dan Angkutan Jalan Kabupaten Banyumas, Bekasi 